Cadernos de Clio, Curitiba, n. ${ }^{\circ}$ 4, 2013

NOTA DE PESQUISA

\title{
LITERATURA E SOCIABILIDADE NA CURITIBA DE DALTON TREVISAN ${ }^{1}$
}

\author{
Pesquisa Coletiva PET-História ${ }^{2}$ \\ Gabriel Elysio Maia Braga
}

No decorrer do ano de 2012, os integrantes do PET História da UFPR, coletivamente, desenvolveram a pesquisa intitulada Literatura e Sociabilidade na Curitiba de Dalton Trevisan a qual foi inspirada no tema da pesquisa do ano anterior, a geração beat norte americana. Devido à sugestão de um dos integrantes do grupo, foram utilizadas as edições da Revista Joaquim como principal objeto de estudo. Editada e idealizada pelo então estudante de direito Dalton Trevisan, a revista possui 21 números publicados entre os anos de $1946-48^{3}$. A revista funcionava em uma gráfica da família Trevisan. Suas edições contaram com a colaboração de escritores e artistas paranaenses da época, como Wilson Martins, Erasmo Pilotto, Poty Lazarotto e Antônio Walger.

\footnotetext{
${ }^{1}$ Resultados da pesquisa apresentados nos eventos $21^{\circ}$ EVINCI (outubro/2013) e I Jornada Paranaense PIBID e PET de História (outubro-novembro/2013).

2 Alunos: Alexandre Cozer, Amanda Cristina Zattera, Augusto Maynardes, Camila Flores Granella, Camila Longo Pleszczak, Davi Pradi, Felipe B. C. C. Bastos, Gabriel Elysio Maia Braga, Gabriela Larocca, Gregório Mazzo, Ivan Lima, Jéssica L. R. Neiva de Lima, Karin Barbosa Joaquim, Kelleny Brasil Rodrigues, Luís Fernando Costa, Mayara Ferneda Mottin, Natascha Eggers, Rayanna Farias, Shirlei Batista dos Santos e Willian Funke. Tutora: Renata Senna Garraffoni.

${ }^{3}$ É interessante ressaltar que as 21 edições da revista - em versão fac-similar encontram-se disponíveis na Biblioteca Pública do Paraná, para consulta.
} 
A revista procura trazer aos seus leitores discussões de âmbito universal, em especial aos chamados moços, a geração do pós-guerra, a qual adquiriu grande aversão ao conflito, colocando a responsabilidade dos fatos na geração precedente. Esse âmbito mundial também aparece com o intuito de aproximar a província do resto do mundo, como consequência, críticas ao chamado “espírito provinciano” são muito frequentes.

Inicialmente foram utilizados como referência trabalhos de Miguel Sanches Neto (1998) e de Roberto Nicolato (2002), ambos sobre a literatura de Trevisan e sua relação com a cidade de Curitiba. Após essas leituras introdutórias, iniciamos as leituras das edições da revista Joaquim. Devido ao destacamento de diferentes temas pelos integrantes do grupo, este foi dividido em três subgrupos, para que diferentes aspectos pudessem ser pesquisados de mais direcionadamente. Dessa forma, cada subgrupo incumbiu-se de um tema, sendo um deles referente à “Guerra”, que procurou entender a visão que a juventude em torno da revista oferecia a respeito dos conflitos e consequências da II Guerra, bem como as discussões artísticas e filosóficas que se formulavam em torno da questão; outro às "Propagandas”, que dividiu-se entre a análise das propagandas de estabelecimentos comerciais e de médicos que apareciam na Revista; e o último à “Curitiba Marginal” que procurou analisar os contos de autoria de Dalton Trevisan presentes nas edições da revista, procurando assim, compreender a cidade por meio dos universos ficcionais oferecidos pelo escritor. 
O subgrupo incumbido do tema "Guerra” deparou-se com uma reflexão acerca da cultura ocidental, em especial às artes. Poty Lazarotto, após voltar de uma viagem a Paris, afirma não conseguir discernir um quadro pós guerra e confessa que, mesmo que o que lhe importava mais era o impacto no campo artístico, os vestígios do conflito ainda estavam presentes em toda parte ${ }^{4}$. A arte também era muito cara aos moços de Curitiba, na qual os simbolistas prevaleciam, aumentando o anseio de produzir um novo tipo de arte que ligasse-os ao resto do mundo afastandose da geração causadora da guerra. Uma das características mais marcantes desse mundo surgido após a II Guerra foi uma nova esperança de mudança e revolução, que, como afirmou Eric Hobsbawn (1995), passou a ser depositada nos jovens, principais protagonistas do século XX. Os intelectuais da Joaquim, seguindo essa linha, buscaram romper com o velho pensamento provinciano, enaltecendo a juventude e valorizando artistas estrangeiros, numa tentativa de mostrar que os moços de Curitiba tinham anseios próprios da sua geração que os aproximavam dos jovens de Paris e Moscou $^{5}$. E o que era comum entre eles era exatamente o fato de serem marcados por este conflito.

Pode ser observado que havia um amplo leque de produtos e serviços promovidos pela revista. Roupas, produtos de higiene e saúde, livrarias, papelarias, serviços de médicos e advogados, joalherias. A análise destes itens gerou um levantamento de suas ocorrências, identificando assim, o número total de estabelecimentos e sua frequência ao longo das edições. Foram destacados 2 tipos principais de anúncios: médicos e ser-

\footnotetext{
${ }^{4}$ Revista Joaquim $\mathrm{n}^{\circ}$ 17, p. 6.

${ }^{5}$ Ver Revista Joaquim, no 9, p. 3 “A geração dos vinte anos na ilha”.
} 
Cadernos de Clio, Curitiba, n. ${ }^{\circ}$ 4, 2013

viços, como por exemplo lojas de roupas. As medicas instigaram-nos a pesquisar a relação dos temas ligados à saúde e à medicina com as propagandas feitas em jornais e revistas da mesma época. O objetivo foi comparar as propagandas apresentadas na revista com as encontradas em jornais, buscando perceber se tais divulgações variavam de acordo com periódico em que se encontravam, os quais possuíam diferentes públicos leitores. Para tal investigação, utilizamos como embasamento teórico Saúde em Frascos: concepções de saúde, doença e cura de Renata Palandri Sigolo Sell (2008), no qual a autora analisa o papel do medicamento industrializado e da indústria farmacêutica na produção de representações sobre saúde e doença entre as décadas de 1930 e 1950. Nossa intenção foi a de investigar se os mesmos temas abordados no texto Saúde em Frascos seriam perceptíveis tanto na Revista Joaquim como nos outros jornais e revistas.

A historiadora Renata Sigolo afirma que as fontes para a realização de sua pesquisa foram, o periódico Revista Medica do Paraná (entre 1931 e 1946) e a Revista Brasileira de Medicina e Farmácia. Por isso, buscamos analisar a Revista Medica do Paraná, dos anos 1946 e 1947 e também a Gazeta do Povo ${ }^{6}$ de Setembro de 1946, que se encontram disponíveis para análises e pesquisas na Biblioteca Pública do Paraná ${ }^{7}$.

Também é interessante observar o modo como os anúncios médicos estão apresentados, muitas vezes sem o endereço do médico referido, e,

\footnotetext{
${ }^{6}$ Tal jornal foi escolhido pelo fato de na época ser o jornal de maior circulação no Paraná.

${ }^{7}$ Infelizmente não tivemos acesso à Revista Brasileira de Medicina e Farmácia e, portanto, não a analisamos.
} 
com o intuito de dar mais crédito ao médico, muitas vezes a alcunha de “professor da universidade do Paraná” aparecia, o que levou ao grupo também a analisar a relação da universidade com a Joaquim, sendo que Dalton Trevisan era estudante de direito e conhecia os discursos mais conservadores dos professores Homero de Barros e Francisco de Paula Soares.

Todas as edições da Joaquim contavam com um ou dois contos, analisados pelo terceiro subgrupo, em sua composição, sendo a maioria de autoria de Dalton Trevisan, ou seja, a alegria e o amor, num sentido positivo, são raros nos contos, geralmente há a prevalência da dor e do sofrimento, chegando ao limiar da morte, como no conto Revista de Jornal ${ }^{8}$ no qual Trevisan, a partir de uma notícia sobre um assassinato cria uma história de desventura amorosa entre assassino e vítima.

Um tema considerado importante foi o espaço. Com base na ideia de topoanálise, desenvolvida por Ozíres Borges Filho (2008), que consiste nas inferências sociológicas, filosóficas e estruturais no âmbito íntimo e social do espaço, este subgrupo buscou analisar o significado que os lugares representados possuíam nas obras do autor. Dois locais de destacam: a igreja e o bar, espaços muito próximos ao cotidiano da população, sendo que o segundo estava ligado a uma ideia de o menino tornar-se homem.

Visto que o uso de revista e periódicos como fonte histórica, sempre pode trazer uma grande possibilidade de observações, a metodologia utilizada pelo grupo foi eficaz. Pode-se perceber que as edições da Joa-

\footnotetext{
${ }^{8}$ Revista Joaquim $\mathrm{n}^{\circ} 2$.
} 
quim eram testemunhas de uma cidade em transformação, sob vários pontos de vista diferentes, seja do comércio, da literatura, da filosofia, da saúde ou da educação. A equipe percebeu que a revista consistia em um espaço no qual jovens buscavam seu espaço frente à geração precedente e novas tendências encontravam seu caminho em meio à tradição. Pudemos constatar também que a própria revista tornou-se uma pequena reprodução do espaço sentimental de seus autores, possibilitando-nos, assim, traçar um mapa sentimental da cidade.

\section{Fontes:}

Revista Joaquim, Curitiba 1946-1948, 21 volumes editados por Dalton Trevisan.

\section{Bibliografia:}

BORGES, Ozíres. Espaço e literature: introdução a topoanálise. In: Anais do XI congresso internacional da ABRALIC. São Paulo: 2008. P. 1 Disponível em: http://www.abralic.org.br/anais/cong2008/AnaisOnline/simposios/pdf/067/OZIRI S_FIL HO.pdf Acessado em 4/4/13, 18:35.

HOBSBAWM, Eric. Era dos Extremos: o breve século XX - 1914-1191. Trad. Marcos Santarrita. São Paulo: Companhia das Letras, 1995

NICOLATO, Roberto. Literatura e cidade - O universo urbano em Dalton Trevisan. (Dissertação Mestrado em Letras). Universidade Federal do Paraná, UFPR, 2002.

SANCHES NETO, Miguel. A reinvenção da província: a revista Joaquim e o espaço de estréia de Dalton Trevisan. Campinas, 1998. Tese (Doutorado em Teoria Literária) - Instituto de Estudos da Linguagem, Unicamp, Campinas, 1998.

SIGOLO, R. P. A Saúde em Frascos: concepções de Saúde, Doença e Cura. Curitiba (1930/45). 1. ed. Curitiba: Aos Quatro Ventos, 1998 